\title{
La traducción y la interpretación a la luz de la ética y la responsabilidad social
}

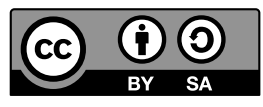

En nuestras sociedades actuales, sujetas a transformaciones rápidas debido a la globalización, los problemas ecológicos, la degradación de la democracia en algunos países y la consecuente proliferación de autoritarismos, la revolución tecnológica digital, las migraciones masivas, el empeoramiento de la desigualdad, el papel predominante del capital y las grandes corporaciones, los conceptos de ética y de responsabilidad social se entrelazan estrechamente volviéndose esenciales en todos los campos y en todas las profesiones. Con la interdependencia del mundo y con las transformaciones mencionadas, la comunicación intercultural, y con ella la traducción y la interpretación, son cada vez más necesarias. Aunque la mayoría de las asociaciones de traductores e intérpretes disponen de sus propios códigos profesionales de ética, la responsabilidad social en el ámbito de la traducción sigue siendo un concepto poco definido, por eso es necesario repensar y revisar los códigos éticos, definir las estrategias y actitudes en los casos concretos y dilucidar cómo se entienden la ética y la responsabilidad social en los diferentes tipos de traducción e interpretación, cómo incorporarlas en la formación y educación de traductores e intérpretes y a qué dilemas se enfrentan en su profesión.

Este número temático de Verba Hispanica pretende ampliar temas sobre la relación entre la ética, la responsabilidad social y la traducción e interpretación, el papel de la traducción e interpretación en su comprensión mutua y en la comunicación intercultural, la importancia de la formación y la educación a la luz de la responsabilidad social y la ética tanto del punto de vista teórico como del de la perspectiva práctica, y también la importancia de la traducción literaria como medio de conocimiento y respeto de diferentes culturas y lenguas. Los nuevos retos a los que nos enfrentamos exigen una reflexión alternativa sobre el papel de los traductores e intérpretes en la sociedad como participantes activos en los procesos comunicativos o como aquellas personas que deben tomar decisiones permanentemente en aras de contribuir, de esta manera, a una comprensión mejor del otro, de lo diferente, y al acercamiento de distintos mundos, ideas y pensamientos. 
Las contribuciones presentadas en este volumen investigan el tema propuesto desde perspectivas muy diferentes y lo abarcan partiendo de diferentes disciplinas: traductología, lingüística, literatura, didáctica. Cinco artículos polemizan los postulados principales de los códigos de ética, de las directrices o protocolos profesionales y reflexionan sobre la responsabilidad social; consecuentemente, también sobre la función del intérprete o del traductor, que ha cambiado, está cambiando y cambiará en el futuro. Basándose en casos y ejemplos concretos, algunos autores llegan a la conclusión de que las directrices relativas a la ética deben reconsiderarse, o que se necesitan protocolos de actuación más específicos para determinadas situaciones de la interpretación. Asimismo, se visibiliza que, con los cambios sociales que mencionamos al principio de la introducción, el intérprete tiene una gran responsabilidad social sobre todo en la interpretación en los servicios públicos o para la comunidad. Las situaciones asimétricas en las situaciones comunicativas de interpretación comunitaria (interlocutores que ejercen su servicio o funciones desde el «poder» e interlocutores sin él) dictan al intérprete una responsabilidad social que puede diferir dependiendo en qué ámbitos y situaciones interpreta y de qué contenidos se trata. Zuzana Balounová abre este bloque de contribuciones con su artículo «Neutrality in public service interpreting: Rethinking the role of public service interpreters ${ }^{1} \gg$ en el que, partiendo de ejemplos y estudios, cuestiona críticamente e interconecta el principio de neutralidad del intérprete en relación a su función y expectativas del cliente en el ámbito sanitario, educativo y social, constatando que muchas situaciones problemáticas surgen por el desconocimiento del trabajo del intérprete en servicios públicos. Philippa May Bennett en «Ethics in translation practice: A comparison of professional codes of conduct ${ }^{2} \gg$ describe la evolución del entendimiento de la ética en la teoría de la traducción del siglo XX al XXI. Mediante el análisis de diferentes códigos de conducta editados por importantes asociaciones internacionales de traductores e intérpretes analiza cuáles de las definiciones teóricas de ética retoman los códigos mencionados y cuál es su utilidad en el trabajo de cada día para los traductores e intérpretes, concluyendo con sus recomendaciones de cambio de estos códigos para que sean más apropiados. Raquel Lázaro-Gutiérrez, Emilia Iglesias-Fernández y Gabriel Cabrera-Méndez se dedican a «Aspectos éticos de los protocolos de actuación en interpretación telefónica», explicando primero las características especiales de esta variante

1 «Neutralidad en la interpretación en el servicio público. Repensar el papel de los intérpretes en servicios públicos».

«Ética en la traducción: una comparación de códigos de conducta». 
de interpretación remota para luego detenerse en los protocolos de actuación que a menudo difieren de los principios éticos más comunes, como neutralidad, confidencialidad, fidelidad y profesionalidad. A este propósito analizan críticamente protocolos adaptados a diferentes clientes usados en la empresa Dualia Teletraducciones. Advierten también sobre la necesidad de prestar más atención a este tipo de interpretación en el marco de los programas universitarios. Rayco H. González-Montesino, Lourdes Calle-Alberdi y Silvia Saavedra-Rodríguez, en su artículo «La formación ética de los futuros intérpretes de lengua de signos española: entre la deontología y la teleología», examinan la interpretación de lengua de signos, una rama antes muy marginada de la interpretación, sin embargo hoy en día cada vez más reconocida. Destacan el cambio de modelos de análisis éticos del trabajo de los intérpretes hacia modelos teleológicos, por lo que también la formación de futuros intérpretes de lengua de signos está transformándose. Presentan un estudio concreto, realizado entre los estudiantes del último año del Grado en Lengua de Signos Española y Comunidad Sorda de la Universidad Rey Juan Carlos de Madrid. Carmen Toledano-Buendía llama la atención en su artículo «Barrera lingüística y victimización secundaria: la (des)atención institucional a las víctimas extranjeras de violencia de género en España» sobre la obligación ética de los estados (España en concreto) de garantizar la ayuda lingüística a la población extranjera que desconoce la lengua española, lo que además es su derecho. Dentro de este colectivo se centra en las mujeres extranjeras víctimas de violencia de género que, si no reciben asistencia lingüística, pueden sufrir una victimización secundaria. La autora parte de los testimonios de las mujeres que sobrevivieron a la violencia de género.

Otros artículos tratan temas diferentes. Amalija Maček y Helena Biffio Zorko se centran en la formación ética de los estudiantes de interpretación de la Universidad de Ljubljana. En «Ethical challenges of interpreter training at the University of Ljubljana. The Faculty of Arts responds to social change» ${ }^{3}$ se resalta que la universidad con sus programas debe responder a los cambios sociales y tecnológicos. En el caso de Eslovenia, por ejemplo, se introducen en el currículum nuevos idiomas y temas que la sociedad necesita.

Andrzej Zieliński en «'Non querades seguir esta carrera que es (de) ufana et llena de vanidat'. Sobre el origen y la evolución del valor deóntico de querer» vuelve su mirada hacia el pasado y desde el punto de vista diacrónico

3 «Desafíos éticos de la formación de intérpretes en la Universidad de Ljubljana. La respuesta de la Facultad de Filosofía y Letras a los cambios sociales». 
comprueba que el valor deóntico de querer en el romance medieval peninsular se debe a la transferencia conceptual del latín tardío NOLI/NOLITE, proclive, a partir del siglo IV, a textos con temática cristiana. Su empleo en el castellano medieval se vincula a la literatura didáctica y sapiencial, en contextos moralizantes cuando el emisor apela al destinatario sobre un comportamiento inadecuado.

Tres artículos se dedican a la traducción literaria en relación a la ética y la responsabilidad social. María Luisa Pérez-Bernardo en su artículo «Didactismo y moralidad en la labor de traducción de Joaquina García Balmaseda (18371911)» analiza la labor traductora de la escritora e importante traductora del siglo XIX, Joaquina García Balmaseda que, por convicciones éticas, acomodó sus traducciones a la «literatura edificante» de la época isabelina, ejerciendo una censura relativa sobre todo a la moral de la época. Karolína Strnadová en «La traducción literaria como compromiso social y cultural: el papel de los traductores de la literatura checa en México», analiza la labor de los traductores de la literatura checa en México valiéndose de los paratextos y las entrevistas con los traductores literarios, ya que en muchos casos el traductor es el que propone la traducción, se ocupa de todo el proceso de la traducción y desempeña un papel de promotor cultural. Por otra parte, Martina Kutková en «Volver a la patria: el renacer del judeoespañol desde la perspectiva de la lengua y cultura checas», también mediante el análisis de los paratextos que acompañan las traducciones del judeoespañol al checo, estudia la génesis y la motivación de estas traducciones y destaca los temas de la ética y la responsabilidad social escondidos en las dos catástrofes que ocurrieron en la historia sefardí -la expulsión de la península ibérica por los Reyes Católicos y el Holocausto-.

Esperamos que este volumen contribuya a una mejor comprensión de los cambios en las profesiones de interpretación y traducción paralelos a las transformaciones sociales y que aporte un valor añadido a las discusiones sobre la ética y responsabilidad social en estas profesiones planteando preguntas a las que todavía no se puede dar una respuesta específica. Asimismo, esperamos que satisfaga la curiosidad científica y profesional y sirva de motivación para futuras investigaciones en este campo.

Jasmina Markič y Marija Uršula Geršak 